\title{
RECEPTORES A 3 DA ADENOSINA: UMA NOVA ABORDAGEM TERAPÊUTICA NO CÂNCER
}

\author{
Alexandra Gaspar, Tiago Silva e Fernanda Borges* \\ Departamento de Química e Bioquímica, Faculdade de Ciências, Universidade do Porto, 4000 Porto, Portugal
}

Recebido em 22/11/10; aceito em 6/4/11; publicado na web em 10/6/11

\begin{abstract}
ADENOSINE $\mathrm{A}_{3}$ RECEPTORS: A NEW THERAPEUTIC APPROACH IN CANCER. Cancer is a multi-factorial disease linked with different initiating causes, cofactors and promoters, and several types of cellular damage. Advancing knowledge on the cellular and molecular biology of the processes that regulate cell proliferation, cell differentiation and cellular responses to external signals, has provided a wealth of information about the cancer cell and how it differs from a normal one. These findings make available a number of potential targets for new therapeutic approaches. The Medicinal Chemistry artwork performed so far in the development of selective and potent adenosine receptor $\mathrm{A}_{3}$ ligands, a current cancer target, will be highlighted in this work.
\end{abstract}

Keywords: cancer; $\mathrm{AR} \mathrm{A}_{3}$; ligands.

\section{INTRODUÇÃO}

\section{Os receptores da adenosina}

Na última década a adenosina (Ado) foi reconhecida como uma molécula de sinalização celular, a qual se liga a receptores específicos presentes na superfície da célula regulando, desta forma, alguns processos fisiológicos. Os receptores da adenosina (RA) encontram-se acoplados a sistemas de transdução intracelulares, por intermédio de proteínas $\mathrm{G}$. Atualmente são conhecidos quatro subtipos de receptores da adenosina (RA), denominados $\mathrm{A}_{1}, \mathrm{~A}_{2 \mathrm{~A}}, \mathrm{~A}_{2 \mathrm{~B}}$ e $\mathrm{A}_{3} .{ }^{1,2}$

Os receptores da adenosina, em analogia com outros receptores acoplados a proteínas G, têm sete domínios transmembranares constituídos por aminoácidos hidrofóbicos, formando cada um deles uma $\alpha$-hélice de aproximadamente 21 a 28 aminoácidos. Os domínios transmembranares estão ligados por três loops intracelulares (IL1, IL2 e IL3) e três loops extracelulares (EL1, EL2 e EL3). O N-terminal do receptor encontra-se na parte extracelular da membrana e o C-terminal na membrana interna. O local de ligação aos diferentes ligantes é formado por um arranjo tridimensional dos domínios da $\alpha$-hélice transmembranares. ${ }^{3} \mathrm{O}$ segmento intracelular do receptor interage com a proteína $\mathrm{G}$, com subsequente ativação do mecanismo intracelular de transdução do sinal.

Os 4 subtipos de receptores são classicamente definidos, através da sua ação no sistema da adenilil ciclase. ${ }^{4}$ Os receptores $\mathrm{A}_{1}$ e $\mathrm{A}_{3}$ interagem com proteínas $\mathrm{G}_{\mathrm{i}}$ inibindo a adenilil ciclase com consequente inibição da produção de cAMP (Adenosina Monofosfato cíclico) intracelular. No entanto, o mecanismo de sinalização dos receptores $A_{2 A}$ e $A_{2 B}$ envolve proteínas da família $G_{s}$ ou $G_{0}$, as quais estimulam a adenilil ciclase promovendo um aumento de cAMP intracelular. ${ }^{5}$ No entanto, outros mensageiros e mecanismos de transdução podem estar associados à transdução de sinal mediado pelos RAs. Por exemplo, a Ado pode exercer uma ação fisiológica em enzimas como cinases como, por exemplo a fosfatidilinositol 3-cinase, a tirosina cinase e cinases mitogénicas ativadas (MAPKs - Mitogen-Activated Protein Kinases), assim como pode ativar a fosfolipase C. ${ }^{6,7}$ A regulação indireta das MAPKs pode ter efeitos nos processos de diferenciação,

*e-mail: fborges@fc.up.pt proliferação e na apoptose celular. Os RAs podem também estar indiretamente correlacionados com os canais iônicos, por exemplo a ativação dos receptores $\mathrm{A}_{1}$ e $\mathrm{A}_{3}$ pode afetar o influxo de cálcio ou o efluxo de potássio. Estes receptores podem ainda afetar a cascata da arrestina, que possui um duplo papel de transmissão de sinal e de autorregulação do receptor. ${ }^{3}$

\section{Os receptores $A_{3}$ da adenosina ( $\left.R A A_{3}\right)$ e o câncer}

O crescimento e a multiplicação celular é um processo determinado, por um lado, pela sua capacidade de replicação e consequente divisão, e por outro, pelos mecanismos apoptóticos que levam à morte celular. De forma geral, o funcionamento normal das células pode sofrer alterações no crescimento e apoptose celular, podendo conduzir a processos de carcinogênese. Perceber os mecanismos que estão na base da proliferação e morte celular é uma área de extrema importância, pois o seu conhecimento melhora a eficácia das terapias direcionadas para um alvo específico. Apesar de já existirem aplicações clínicas de inibidores do ciclo celular subsiste ainda uma necessidade urgente e emergente de procura de novos alvos, assim como do desenvolvimento de novas entidades químicas que possam interagir especificamente em vários locais do ciclo celular. ${ }^{8,9}$

Os receptores da adenosina têm vindo a ser extensivamente estudados como potenciais alvos para o tratamento de inúmeras doenças, como a de Parkinson, a esquizofrenia e a isquemia. ${ }^{10,11}$ $\mathrm{Na}$ última década surgiram evidências do envolvimento da Ado na apoptose e no ciclo celular. Acresce-se que o receptor $\mathrm{A}_{3}$ se encontra com uma expressão elevada nos tecidos tumorais e que os seus níveis de expressão, em variadíssimos tipos de tumor, podem estar correlacionados com o grau de severidade da doença. Os dados obtidos até à data permitiram colocar a hipótese do controlo da morte celular ser mediado pelo receptor $\mathrm{A}_{3} \cdot{ }^{12-14}$ Diversos autores demonstraram ainda que baixas concentrações de agonistas do RA $\mathrm{A}_{3}$ têm efeitos protetores, enquanto que concentrações elevadas podem induzir apoptose. É sabido que a estimulação do receptor $\mathrm{A}_{3}$ com agonistas como o IB-MECA ( $N^{6}$-(3-iodobenzil)-adenosina$5^{\prime}$ - $N$-metiluronamida) e o tio-Cl-IB-MECA inibem a proliferação celular de diferentes células cancerígenas. ${ }^{12,15}$ 
Uma das maiores dificuldades no tratamento das doenças oncológicas mais incidentes na população (câncer do cólon, pulmão, mama e próstata) é o fato de se formarem tumores sólidos. As células cancerígenas crescem a um ritmo mais acelerado e descoordenado $\mathrm{e}$, por isso, a sua rede vascular é normalmente inadequada, pouco difusa e os vasos sanguíneos são normalmente insuficientes e de calibre insuficiente. Desta forma, a maioria dos tumores sólidos não recebe oxigênio suficiente e as células encontram-se em hipóxia. ${ }^{12,16}$ Nestas condições, e devido a vários mecanismos, que ocorrem sinergicamente, como a regulação das enzimas envolvidas na biossíntese e o transporte da Ado intracelular para o meio extracelular, ocorre a acumulação de Ado extracelular com consequente elevação dos seus níveis no fluido extracelular de tumores. ${ }^{12,17}$ Por outro lado, como resultado da resposta celular ao estado de hipóxia o fator HIF-1 (fator induzido por hipóxia) é estabilizado. Existem duas isoformas deste fator, uma constitutiva (HIF-1 $\beta$ ) e outra induzida (HIF-1 $\alpha$ ). Foi demonstrado, por ensaios imuno-histoquímicos, que a isoforma HIF- $1 \alpha$ se encontra em elevadas concentrações em tumores humanos, tendo um importante papel na atividade biológica tumoral, como a angiogenese, invasividade e alterações energéticas e metabólicas. ${ }^{14} \mathrm{O}$ aumento da produção de HIF-1 $\alpha$ via ativação do receptor da adenosina $\mathrm{A}_{3}$, e adicionalmente um aumento de angiopoetina-2 em mastócitos e células melanômicas, permite pressupor que a Ado esteja intimamente ligada com o processo de angiogenese. ${ }^{18-20}$ Assim, tendo em conta os efeitos descritos foi proposta uma nova abordagem terapêutica no tratamento de alguns tipos de câncer, através do uso de antagonistas do receptor $\mathrm{A}_{3}$. Especula-se que estes possam de alguma forma bloquear a produção de HIF-1 $\alpha$ e angiopoietina- $2 .{ }^{14}$ Apesar de existirem cada vez mais estudos relativos ao envolvimento da adenosina em processos tumorais, existem ainda muito poucos compostos cujo screening como potenciais agentes anticancerígenos esteja a ser avaliado com base no "sistema adenosinérgico". ${ }^{21}$

\section{LIGANTES DOS RECEPTORES A A $_{3}$ DA ADENOSINA}

O desenvolvimento de novos ligantes (agonistas, antagonistas ou alostéricos) capazes de modular o RA $\mathrm{A}_{3}$ é hoje em dia uma área de pesquisa emergente na Química Medicinal. Assim, neste trabalho, optou-se por apresentar os resultados de pesquisa no desenvolvimento de ligantes RA $\mathrm{A}_{3}$ considerados mais promissórios. A divisão de classes efetuada foi adaptada dos trabalhos recentemente publicados por Jacobson et al. ${ }^{3}$ e Baraldi et al.. ${ }^{22}$ As modificações introduzidas permitem, no nosso entender, que o investigador possua uma visão mais simplificada da arte da descoberta e desenvolvimento dos ligantes $\mathrm{AR} \mathrm{A}_{3}$.

De salientar que dos quatro receptores da adenosina o RA $\mathrm{A}_{3}$ é o que apresenta maior dependência da espécie. ${ }^{23}$ Esta variabilidade é considerada de particular importância para os estudos de relação estrutura-atividade (REA).

\section{Agonistas RA A}

Os agonistas desenvolvidos para o RA $\mathrm{A}_{3}$ foram essencialmente baseados na estrutura da adenina. No entanto, é importante referir que outros tipos de ligantes foram também propostos, sendo por esta razão descritos neste trabalho. A investigação desenvolvida até à data permitiu obter ligantes potentes e seletivos para os RA $\mathrm{A}_{3}$ alguns dos quais já estão em fase clínica.

\section{Derivados de purinas modificados}

A abordagem inicial para identificar e otimizar, em relação à potência e seletividade, os primeiros agonistas $\mathrm{A}_{3}$ envolveu um screening extenso de vários derivados nucleosídicos e estudos de REA. ${ }^{24}$

\section{Derivados de adenina}

Tendo como base a molécula da Ado efetuaram-se várias modificações na sua estrutura, tendo-se concluído que os derivados mais potentes como agonistas RA $\mathrm{A}_{3}$ eram $\mathrm{N}^{6}$-monoamino e/ ou 5'- $\mathrm{N}$-etilcarboxamido substituídos. ${ }^{10,25}$ Ao longo deste tipo de estudos foi ainda demonstrado que a combinação dos dois tipos de substituições numa só estrutura conduzia, de forma geral, a um aumento da afinidade do ligante ao receptor. O primeiro agonista resultante deste tipo de estudos, apesar de não seletivo, foi o NECA (Adenosina-5' $-N$-etilcarboxamida). A sua seletividade para o RA $\mathrm{A}_{3}$ foi posteriormente melhorada com a introdução de uma cadeia metiluronamida em 5'- e um grupo retirador de elétrons na posição 3 - da cadeia lateral do grupo $N^{6}$-benzila. Esta combinação de substituições levou ao desenvolvimento de um novo agonista, denominado $N^{6}$-(3-iodobenzil)-adenosina-5' $-N$-metiluronamida (IB-MECA), atualmente usado como o agonista padrão para os estudos de screening biológico para o RA $\mathrm{A}_{3}$. A introdução de um halogênio em $\mathrm{C} 2$ na estrutura do IB-MECA deu origem ao 2-Cl-IB-MECA e um aumento significativo na seletividade e afinidade para os RA A . Este composto está em estudos clínicos de fase II para o tratamento de artrite reumatoide e câncer. ${ }^{24}$ De referir ainda um derivado do IB-MECA (I-AB-MECA) o qual é amplamente usado como radioligante para os estudos RA A $\mathrm{A}_{3}$.

Outros estudos para o desenvolvimento de agonistas do tipo nucleosideo foram efetuados centrando-se em modificações na posição $N^{6}, \mathrm{C} 2$ e ribose da Ado.

Uma ampla série de derivados da adenosina modificados em $N^{6}$ como, por exemplo, derivados $N^{6}$-aril(alquila) substituídos foram sintetizados e a sua atividade avaliada. ${ }^{23,26} \mathrm{O}$ estudo REA permitiu concluir que uma monoamino substituição em $N^{6}$ por um grupo metila (composto 1, Figura 1A) ou metoxila (composto 2, Figura 1A) permitiu aumentar quer a potência quer a seletividade dos derivados para o RA A . É no entanto importante salientar que a substituição na referida posição por cadeias com maior número de carbonos, quer lineares quer ramificadas, conduz a uma diminuição da seletividade. Estes estudos demonstraram ainda que o derivado $N^{6}$-benziladenosina (composto 3, Figura 1A) revelou ser um agonista seletivo para o RA $\mathrm{A}_{3}$. Este fato conduziu ao estudo da influência de substituições de natureza química diversa no anel $N^{6}$ - benzílico, concluindo-se que a introdução de um halogêneo ( $\mathrm{Cl}$ ou I) (composto 4, Figura 1A) na posição 3- do anel aromático melhorava a seletividade para o receptor. Importante salientar que os estudos efetuados permitiram verificar que a introdução de um grupo feniletila em $N^{6}$ originava um aumento da atividade agonista e uma perda de seletividade. ${ }^{24}$ Variações estruturais efetuadas em torno do referido derivado como, por exemplo, a introdução de um grupo ciclopropila (composto 5, Figura 1A), restringindo assim a rotação da molécula, deram origem a um agonista potente e seletivo. A adição de um grupo $\mathrm{CF}_{3}$ na posição para do anel aromático presente em $N^{6}$ originou também um agonista potente e seletivo. ${ }^{27}$ Baraldi et al.${ }^{27}$ sintetizaram derivados cuja substituição em $N^{6}$ envolvia grupos aminossulfonilfenila (composto 6, Figura 1A) tendo verificado um incremento de seletividade com a modificação estrutural do grupo sulfonamida (e.g. inclusão de cadeias alquílicas curtas como o grupo etila ou alila). A adição de anéis heterocíclicos saturados, como a piperidina ou a morfolina, ao grupo sulfonamida também levou a um aumento de seletividade para o RA $\mathrm{A}_{3}$.

As modificações estruturais na posição C2 da adenina (Figura 1B) foram inicialmente efetuadas com o objetivo de desenvolver ligantes mais potentes para o RA $\mathrm{A}_{2 \mathrm{~A}} \cdot{ }^{28}$ No entanto, algumas alterações efetuadas, como a introdução de cloro na posição 2 (composto 7 , Figura 1B), levaram à obtenção de compostos seletivos para o RA $\mathrm{A}_{3}$. É ainda importante salientar que a introdução do grupo $-\mathrm{SCH}_{3}$ na posição $\mathrm{C} 2$, quando não acompanhada por outras modificações 

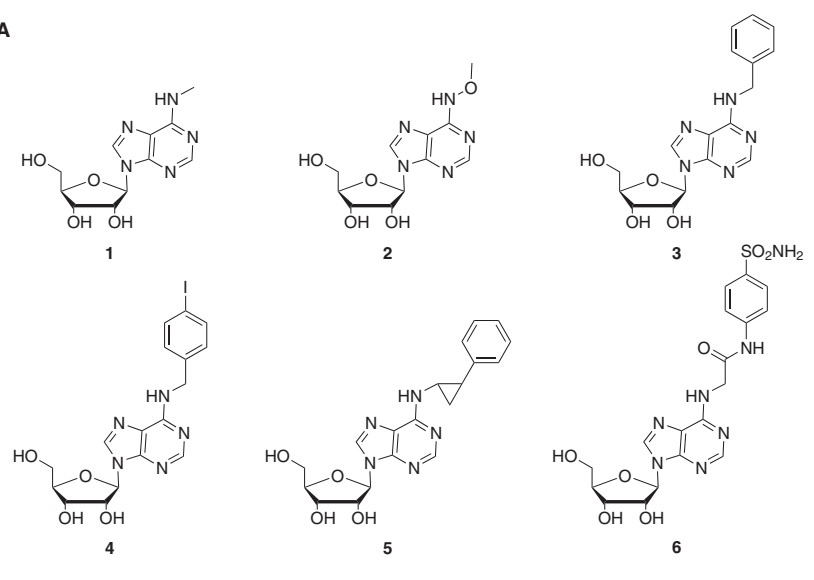

B
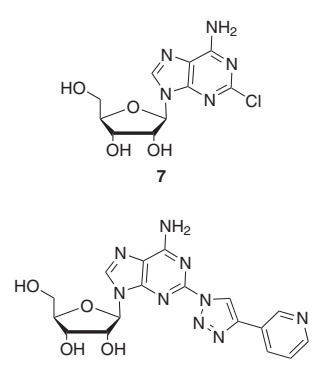

9

c

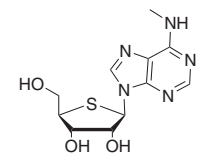

11

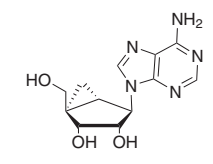

12
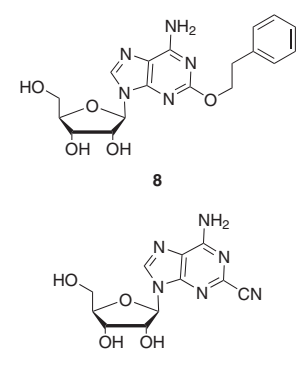

10

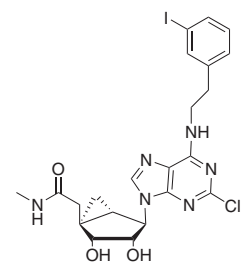

13
Figura 1. Modificações estruturais na posição $N^{6}(A)$, na posição $C 2(B)$ e no núcleo da ribose $(C)$ de agonistas baseados na adenina

estruturais, origina uma diminuição da afinidade ao receptor. ${ }^{24} \mathrm{~A}$ maioria das modificações estruturais realizadas na posição 2- originaram um decréscimo da afinidade para o RA $\mathrm{A}_{3}$. No entanto, a introdução em C2 de substituintes com funções do tipo éter como, por exemplo, a introdução de um grupo feniletiloxila (composto 8, Figura 1B), revelou serem muito produtivas para a ligação ao receptor. Outro tipo de derivados possuindo substituintes do tipo heterociclo como, por exemplo, a 2-triazol-1-il-5'- $N$-etiluronamida adenosina (composto 9, Figura 1B), revelou serem agonistas potentes e seletivos para RA A ${ }_{3} \cdot{ }^{29,30}$

Foram ainda sintetizados compostos cujas modificações foram realizadas nas posições $N^{6}$ e C2 do anel da Ado. Ohno et al. ${ }^{31}$ descobriram que a combinação do grupo 2-ciano com diferentes substituintes na posição $N^{6}$ conduzia a efeitos farmacológicos distintos: o 2-ciano- $N^{6}$-(3-iodobenzil) adenosina, é um antagonista, enquanto que o 2-ciano- $N^{6}$-metiladenosina (composto 10 , Figura 1B) é um agonista seletivo para o $\mathrm{RA} \mathrm{A}_{3} \cdot{ }^{24}$

Nos estudos anteriormente descritos o núcleo da ribose foi geralmente mantido intato. No entanto, este anel foi modificado em diversos estudos, tendo-se concluído que os grupos hidroxila nas posições 2'-e 3'- eram necessários para a sua ligação, por ligação de hidrogénio, ao RA $\mathrm{A}_{3} \cdot{ }^{28}$ Posteriormente foi verificado que no caso dos derivados $N^{6}$-substítuidos o grupo hidroxila em $3^{\prime}$ - pode ser substituído por outros grupos funcionais (e.g. grupo amina) sem perda da atividade farmacológica. ${ }^{32,33}$ É ainda importante salientar que os estudos de relação estrutura-atividade permitiram concluir que a posição $5^{\prime}$ do núcleo da ribose deve possuir alguma flexibilidade conformacional. A presença de uma uronamida ou $N$-alquiluronamida nesta posição parece proporcionar os graus de liberdade necessários ao ligante quando da ativação do receptor. ${ }^{34}$ Outras modificações químicas efetuadas nesta posição (e.g. introdução de um grupo alquiltioéter) também conduziram à obtenção de agonistas RA $\mathrm{A}_{3}$. Para alguns derivados verificou-se ainda que oxigênio endocíclico pode ser substituído por um átomo de enxofre (composto 11, Figura 1C) ou por um grupo metilénico (composto 12, Figura 1C). ${ }^{24,35}$ Os derivados tio apresentam regra geral a mesma potência, ou são ligeiramente mais potentes que os seus análogos oxigenados. No entanto, é importante salientar que as modificações estruturais efetuadas nas posições $N^{6}$ e C2 podem modular a ação destes compostos transformando-os em potentes antagonistas. ${ }^{28}$

Destes estudos destaca-se o composto 13 (Figura 1C) o qual é usado como radioligante em estudos do RA $\mathrm{A}_{3}$. Este composto possui uma estrutura mista entre os agonistas anteriormente referidos e os derivados metanocarbonucleosídeos.

\section{Derivados da xantina}

Para além dos derivados da Ado uma outra classe de compostos, denominada genericamente como derivados da xantina-7-ribosídeo (composto 14, Figura 2A), foi usada como protótipo para o desenvolvimento de agonistas RA $\mathrm{A}_{3}$. Apesar da 1,3-dialquilxantina ser classicamente considerada um antagonista dos RA verificou-se que a introdução de um açúcar na posição 7 resulta em agonismo relativamente a $\mathrm{RA} \mathrm{A}_{3}$. A afinidade destes compostos para o receptor é dependente do tipo de substituintes localizados nas posições $N^{1}$ e $N^{3}$. Por exemplo, a introdução do grupo butila produz um aumento na afinidade para o receptor $\mathrm{A}_{3}$ assim como introdução da cadeia 5 '-metilcarboxamida na ribose. ${ }^{10,24}$
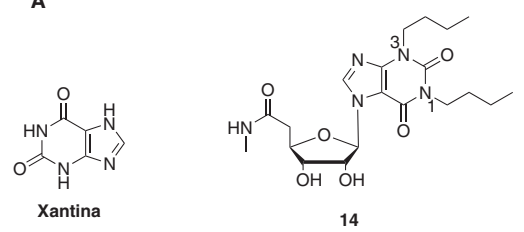

Figura 2. Agonistas baseados no núcleo da xantina (A) e do tipo não nucleosídico $(B)$

\section{Agonistas não nucleosídicos}

Apesar da maioria dos agonistas dos RA terem derivado de modificações do ligante endógeno, a adenosina, uma série de agonistas não nucleosídicos foram recentemente descobertos. As modificações químicas efetuadas em derivados da piridina-3,5-dicarbonitrila (e.g. composto 15, Figura 2B) permitiram desenvolver agonistas potentes, do tipo não seletivo, para RA A ${ }_{3} \cdot{ }^{36,37}$

\section{Antagonistas do $\mathbf{R A}_{3}$}

Nos últimos anos foram reunidos esforços no desenho racional e desenvolvimento de potentes antagonistas dos $\mathrm{RA} \mathrm{A}_{3} \cdot{ }^{5,10,38}$ As tentativas iniciais de descoberta de antagonistas $\mathrm{A}_{3}$ foram inicialmente focadas no screening de derivados da xantina e análogos das purinas, os quais não possuíam quer afinidade quer seletividade significativa para o receptor $\mathrm{A}_{3}$ da adenosina. ${ }^{39}$ Partindo destas observações experimentais outras classes de compostos, foram sintetizadas e biologicamente avaliadas, tendo sido vários compostos identificados como antagonistas RA $\mathrm{A}_{3}$. Estes compostos do tipo heterocíclico foram classificados em várias famílias químicas: derivados de fla- 
vonoides; derivados da 1,4-di-hidropiridina, da piridina e da pirimidina; derivados da triazoloquinazolina; derivados da isoquinolina e quinazolina e, derivados da pirazoloquinolina, triazoloquinoxalina e pirazolotriazolopirimidina.

\section{Heterociclos com oxigênio}

\section{Flavonoides e derivados}

Os flavonoides e derivados foram considerados estruturas promissoras como antagonistas do receptor $\mathrm{A}_{3}$, visto terem evidenciado possuir uma afinidade de ordem nanomolar para o receptor $\mathrm{A}_{3}$. Estes compostos apresentaram uma seletividade para o receptor $\mathrm{A}_{3}$ humano significativamente superior à obtida nos ensaios efetuados em camundongo. ${ }^{40}$ De salientar que a variabilidade interespecífica nas afinidades de ligação é consistente com a baixa homologia entre as sequências proteicas do receptor da adenosina $\mathrm{A}_{3}$ humano e de camundongo. ${ }^{41,42}$

Os estudos de relação estrutura-atividade efetuados para este grupo de compostos (Figura 3) permitiram verificar que a presença de grupos hidroxilas livres leva a uma diminuição de afinidade para o RA A $_{3}$. Por exemplo, a galangina (composto 16, Figura 3) tem menor afinidade para RA A $\mathrm{A}_{3}$ que o seu derivado metoxilado, (composto 17, Figura 3). Verificou-se ainda que quanto mais extenso for o número de grupos metoxila maior é a seletividade para o hA 3 (composto 18, Figura 3). ${ }^{43}$ Tendo como base a otimização do núcleo flavona outros derivados foram sintetizados. Assim, observou-se que a substituição do grupo $\mathrm{OCH}_{3}$ da morina (composto 17, Figura 3) pelo grupo $-\mathrm{OC}_{3} \mathrm{H}_{8}$ (composto 19, Figura 3) levou a um incremento da afinidade para receptores $\mathrm{hA}_{3}$, com uma perda concomitante da seletividade em relação aos outros subtipos de receptores da adenosina. ${ }^{40}$ Os mesmos autores demonstraram que a introdução de átomos de cloro nas posições 3 e 6 do núcleo flavonoide levou a um aumento da relação potência $v s$ seletividade (compostos 20 e 21, Figura 3). Um aumento da seletividade foi também verificado como resultado da introdução de grupos volumosos nas posições orto do grupo fenila posicionado em C2 (composto 21, Figura 3).
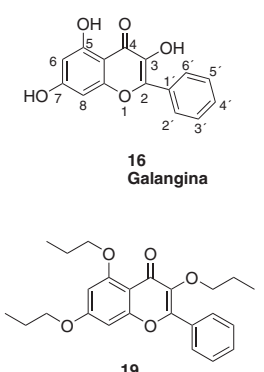
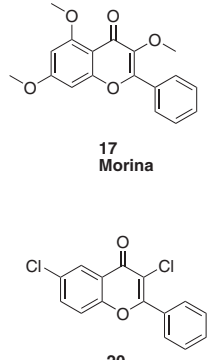
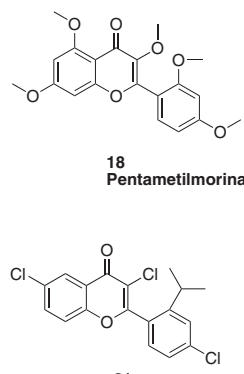

Figura 3. Antagonistas derivados de flavonoides

\section{Heterociclos com nitrogênio}

\section{Derivados da 1,4-di-hidropiridina, piridina e pirimidina}

As di-hidropiridinas apresentam afinidade para vários locais de ligação, tendo sido extensivamente estudadas como potentes bloqueadores dos canais de $\mathrm{Ca}^{2+}$ do tipo L (composto 22, Figura 4A). ${ }^{44}$ Os estudos de relação estrutura-atividade para o RA $\mathrm{A}_{3}$ efetuados para este tipo de derivados permitiram verificar que a introdução de grupos nas posições 4-, 5- e 6- do anel heterocíclico é bem tolerada (compostos 23-25, Figura 4A). A inclusão de um espaçador na posição 4-, nomeadamente o grupo estiril (composto 23, Figura 4A), conduz a um aumento da afinidade para RA $\mathrm{A}_{3} \cdot{ }^{10}$ Por sua vez, a introdução de um grupo feniletinila na posição 4- e de um grupo éster benzílico na posição 3- do anel heterocíclico também se traduziu num aumento

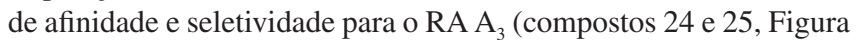

4A). Verificou-se também que a introdução de um grupo retirador de elétrons (como o grupo nitro) na posição 4' do éster benzílico do composto 24 (Figura 4A) originou um aumento na seletividade e afinidade para o receptor $A_{3}$ humano (composto 25, Figura 4A) ${ }^{45}$ Outras modificações estruturais efetuadas, como a inclusão de grupos heterocíclicos na posição 4- e de grupos aminolaquila e tioalquila nas posições 3- e 5-, não foram consideradas benéficas quer em termos de afinidade quer de seletividade. ${ }^{22}$

A
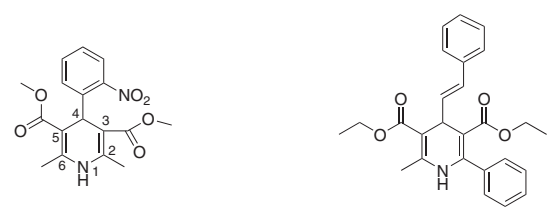

$\stackrel{22}{\text { Nifedipina }}$

23
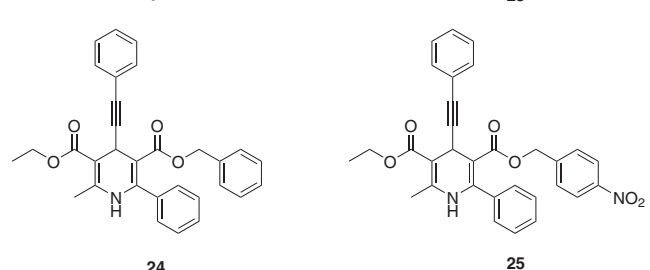

B
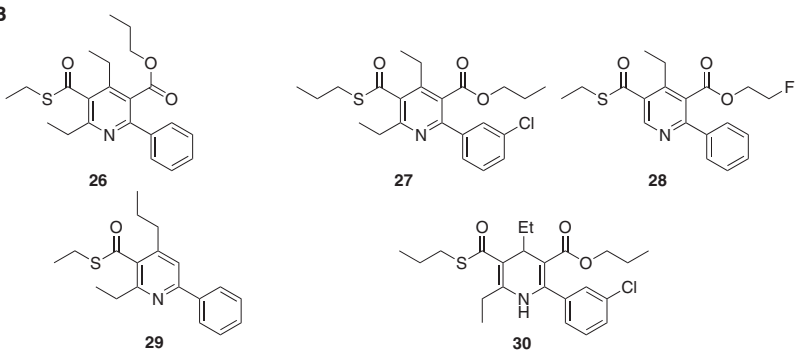

C
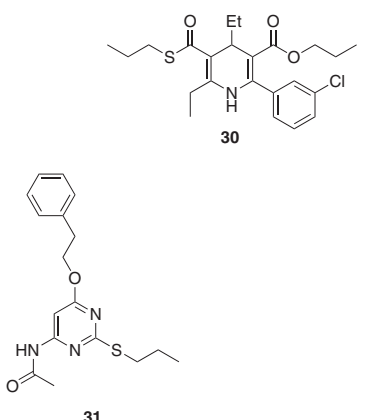

Figura 4. Antagonistas derivados da 1,4-di-hidropiridina (A), da piridina (B) e da pirimidina $(C)$

No caso dos derivados da piridina verificou-se que os grupos volumosos que foram introduzidos na posição 4- das di-hidropiridinas (que aumentam a afinidade para o receptor $\mathrm{A}_{3}$ ) não tiveram o mesmo efeito na atividade. A diferença dos efeitos observados foi justificada pela modificação da hibridização em $\mathrm{C}-4$, de $\mathrm{sp}^{3}$ para $\mathrm{sp}^{2}$, e consequente alteração do ângulo da ligação C5-C4-R4. ${ }^{46}$ Dos vários estudos efetuados concluiu-se que para se manter a afinidade e seletividade RA $\mathrm{A}_{3}$ devem ser introduzidos grupos menos volumosos, os quais não exerçam um impedimento estérico significativo (compostos 2630, Figura 4B). De salientar que o composto mais potente desta série (composto 30, Figura 4B) possui na posição 4- grupos alquila. ${ }^{47} \mathrm{Os}$ derivados da piridina referidos apresentam ainda seletividade para o receptor $\mathrm{A}_{3}$ de camundongo, contrariamente aos compostos descritos anteriormente, sendo por isso mais usados em estudos in vitro do papel fisiológico do receptor $\mathrm{A}_{3} \cdot{ }^{10}$

$\mathrm{O}$ desenho racional de derivados da pirimidinas foi efetuado a partir de estudos de REA desenvolvidos após uma pesquisa efetuada a partir de uma base de dados. O composto mais ativo foi o composto 31 (Figura 4C), o qual possui substituintes do tipo propilsulfanila, 
acetoamino e fenetilóxido nas posições 2-, 4- e 6- do núcleo pirimidínico, respetivamente. ${ }^{47}$

\section{Heterociclos bicíclicos}

\section{Derivados da triazoloquinazolina}

A descoberta desta classe de compostos como antagonistas RA $\mathrm{A}_{3}$ foi baseada nos dados experimentais obtidos com o composto 32 (Figura 5A), o qual se liga ao receptor com elevada afinidade, mas no entanto sem a seletividade pretendida. Tomando o composto 32 como líder de série, foi efetuado um estudo de REA em que o grupo amino foi acilado (compostos 33-38, Figura 5A). ${ }^{48} \mathrm{O}$ resultado deste estudo permitiu concluir que a introdução de uma cadeia acila favorece a afinidade e seletividade para o receptor $\mathrm{A}_{3}$. Estudos de REA quantitativos (REAQ) efetuados posteriormente permitiram verificar que as caraterísticas eletrónicas e espaciais, em oposição às propriedades hidrofóbicas, dos substituintes dos derivados das triazoloquinazolinas têm uma importante contribuição na ligação do ligante ao receptor. Com base nestes dados procedeu-se à remoção do átomo de cloro situado na posição 9- e fez-se a substituição dos grupos 5-fenilacetomida e 2-furila por uma cadeia linear e um anel 4-bromofenila, respetivamente. Obteve-se assim o composto 39 (Figura $5 \mathrm{~A}$ ) como um potente e seletivo antagonista $\mathrm{RA} \mathrm{A}_{3}{ }^{49}$

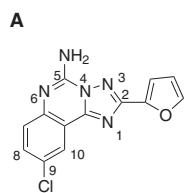

32

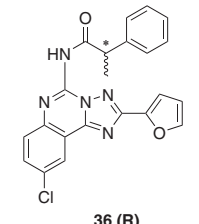

36 (R)
37 (S)

B

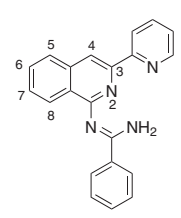

40

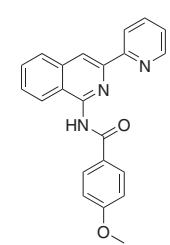

43

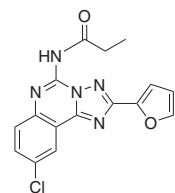

33

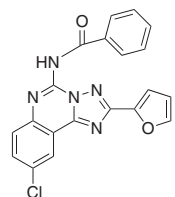

34

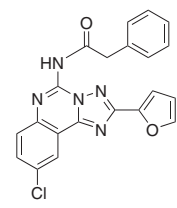

35

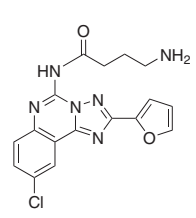

38
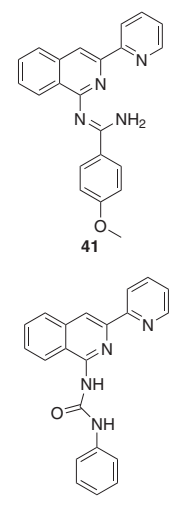

44

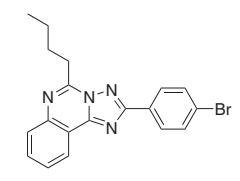

39

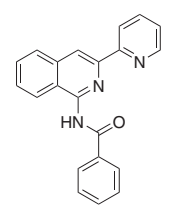

42

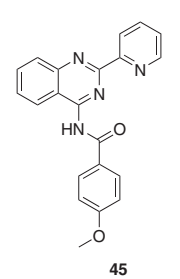

Figura 5. Antagonistas derivados da triazoloquinazolina (A), da isoquinolina e quinazolina $(B)$

\section{Derivados da isoquinolina e da quinazolina}

Os estudos de relação estrutura-atividade efetuados para os derivados da isoquinolina mostraram que para se obter um incremento na afinidade e seletividade para o receptor $\mathrm{A}_{3}$ é essencial a presença de um grupo fenila na posição 1 -, ligado por um espaçador do tipo amidina, do núcleo central da isoquinolina

(compostos 40 e 41, Figura 5B). ${ }^{50-52}$ A substituição do espaçador amidina por um grupo amida (compostos 42-43, Figuras 5B e C) levou à obtenção de derivados com propriedades semelhantes aos descritos anteriormente, no entanto, a introdução de um grupo doador de elétrons $\left(-\mathrm{OCH}_{3}\right)$ na posição para do grupo fenila (composto 43, Figura 5B) levou a um incremento de atividade, quer de afinidade quer de seletividade, para o receptor $A_{3}$. A presença do grupo benzamido faz com que estes compostos possam existir sob duas formas tautoméricas - a forma amida ou a forma iminol - tendo sido verificado que a presença de um grupo doador de elétrons no grupo fenila existente no espaçador é capaz de determinar a forma tautomérica predominante do ligante. Como resultado de diversos estudos conformacionais e de ressonância magnética nuclear foi possível obter o composto 44 (Figura 5B), o qual possui um grupo piridinila na posição 2- e um grupo fenila, substituído na posição 1-, ligado ao núcleo da isoquinolina por um espaçador do tipo ureia ${ }^{22}$ Os estudos de biososterismo realizados permitiram concluir que o incremento de átomos de nitrogênio no heterociclo não originava uma melhoria significativa da interação com o receptor $\mathrm{A}_{3}$. Destes estudos salienta-se o composto 45 (Figura 5B) que possui uma afinidade para o receptor na ordem de nanomolar ${ }^{50}$

\section{Derivados da pirazoloquinolina, da triazoloquinoxalina e da pirazolotriazolopirimidina}

Colotta et al. ${ }^{53}$ efetuaram estudos de REA em derivados de pirazoloquinolinas tendo concluído que o derivado com um substituinte do tipo 4-benzoilamido (composto 46, Figura 6A) foi o que apresentou melhor perfil como antagonista $\mathrm{RA} \mathrm{A}_{3}$. Um estudo posterior ${ }^{54}$ indicou que a afinidade/seletividade do ligante podia ser incrementada pela introdução na posição 4- de grupos acilamino volumosos e lipofílicos. Os estudos com isômeros estruturais efetuados por Baraldi et al. ${ }^{38}$ conduziram também à descoberta de potentes e seletivos antagonistas $\mathrm{RAA}_{3}$. Os derivados mais potentes e seletivos obtidos foram aqueles que possuíam substituintes na posição 4 - do anel $\mathrm{N}$-2-fenila do tipo metila ou metoxila.
A
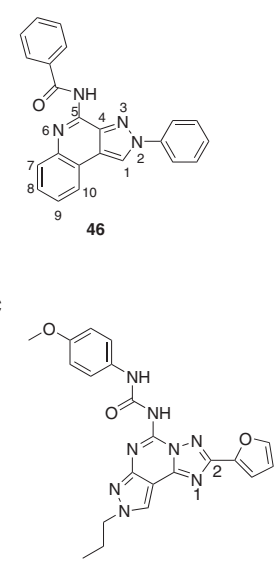

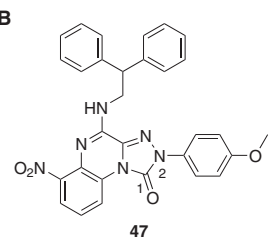

47

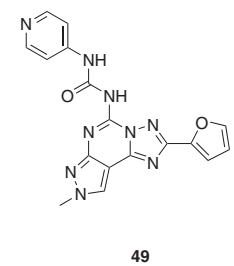

Figura 6. Antagonistas derivados da pirazoloquinolina (A), da triazoloquinoxalina $(B)$ e da pirazolotriazolopirimidina $(C)$

O desenvolvimento de novos scaffolds baseados na triazoloquinoxalina (composto 47, Figura 6B) para antagonistas RA $\mathrm{A}_{3}$ foi também efetuado. ${ }^{6,55} \mathrm{O}$ esforço sintético desenvolvido e o estabelecimento de REA associadas a estudos de modelagem molecular permitiram a identificação dos requisitos estruturais adequados à otimização do líder (e.g. presença de um grupo carbonila (extra) nuclear e grupos 4-acilamina volumosos e lipofilicos). 
Uma grande variedade de derivados da pirazolotriazolopirimidina foram também sintetizados para efetuar estudos de REA. As modificações químicas envolveram, de forma geral, substituições sistemáticas nas posições C2, C5, C9, $N^{7}$ e $N^{8}$. O composto 48 (Figura 6C) foi o que exibiu a melhor relação de afinidade $v s$ seletividade.$^{56}$ No sentido de aumentar a sua solubilidade em água foi ainda efetuada uma substituição bioisostérica do anel fenila do gupo 5-fenilcarbamoila pelo grupo piridila (composto 49, Figura 6C). Os estudos posteriormente efetuados com os derivados obtidos, apoiados por estudos de modelização receptor-ligante, permitiram concluir que os objetivos foram positivamente alcançados. ${ }^{57}$

\section{Derivados purínicos}

\section{Baseados na adenina}

A primeira classe de antagonistas seletivos $\mathrm{RA} \mathrm{A}_{3}$ possuindo uma estrutura bicíclica baseada no núcleo da adenina foi proposta em 2005 por Biagi et al..$^{58}$ Os estudos de REA foram efetuados a partir da otimização sistemática da natureza química dos substituintes localizados nas posições 2, 6- e 9 do composto heterocíclico. Como resultado deste estudo salienta-se como melhor candidato o composto 50 (Figura 7A). Com base no mesmo tipo de estudos Joshi et al. ${ }^{25}$ propuseram o composto 51 (Figura 7A), o qual possui um grupo ciclo-hexila na posição $N^{6}$ e um grupo feniloxila na posição C2 da adenina, como um bom antagonista $\mathrm{RA} \mathrm{A}_{3}$. Triazolopurinas foram ainda obtidas por Okamura et al. ${ }^{49,59}$ os quais propuseram o composto 52 (Figura 7A) como o mais interessante antagonista RA $\mathrm{A}_{3}$.

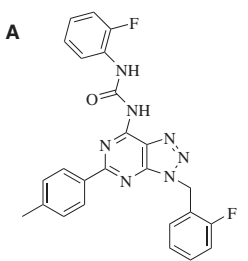

50

B

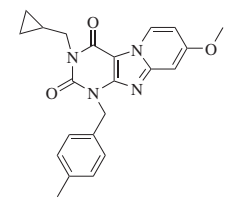

C

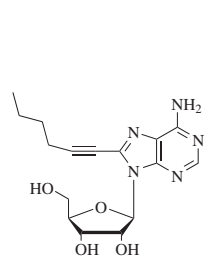

56

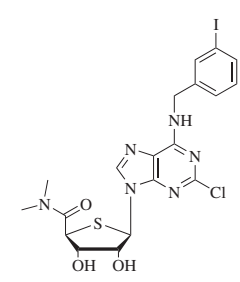

59

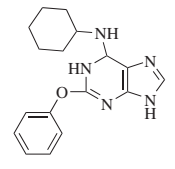

51

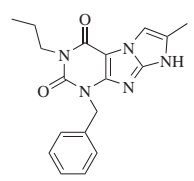

54
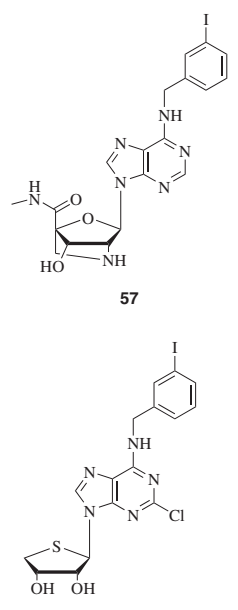

60

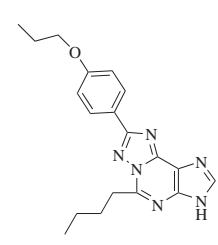

52

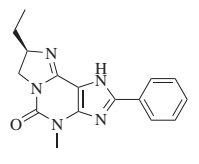

55
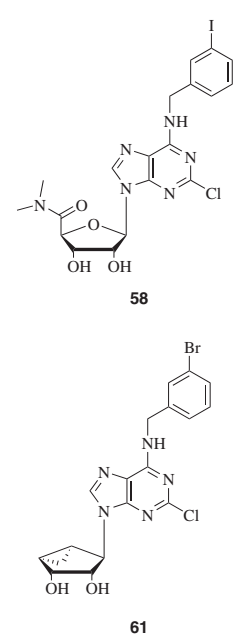

Figura 7. Antagonistas derivados da adenina (A), xantina (B) e nucleosídos (C)

\section{$\underline{\text { Baseados na xantina }}$}

Os antagonistas de origem natural para os RAs, como a cafeína e teofilina, têm de forma geral baixa afinidade para o receptor RA $\mathrm{A}_{3}$. No entanto. é importante ressaltar que nesta última década vários derivados das xantinas foram descobertos como antagonistas $\mathrm{A}_{3} \cdot{ }^{22}$ A título de exemplo salientam-se os compostos 53 e 54 (Figura 7B) obtidos durante os estudos REA e de modelagem molecular efetuados por Priego et al..$^{60}$ e Baraldi et al. ${ }^{61}$ como potentes e seletivos RA A 3 . Müller et al. ${ }^{62}$ também sintetizaram uma série de derivados baseados no núcleo da xantina. Salienta-se deste estudo o composto 55 (Figura 7B) que, para além da afinidade e seletividade para o receptor, se carateriza por uma melhor solubilidade, devido à introdução de um átomo de nitrogênio básico protonável em pH fisiológico.

\section{Derivados nucleosídicos}

A manipulação estrutural efetuada nas diferentes posições da adenosina, notadamente em $\mathrm{C} 2, N^{6}$ e núcleo da ribose, levou à obtenção de uma série de ligantes RA $\mathrm{A}_{3}$ com diferentes perfis de potência, seletividade e eficácia. Ao longo desta última década os resultados obtidos também demonstraram que a combinação destas modificações modula o comportamento deste tipo de compostos como agonistas ou antagonistas.

O primeiro exemplo da aplicação de derivados da adenosina como antagonistas $\mathrm{RA} \mathrm{A}_{3}$ foi descrito por Volpini et al.. ${ }^{63} \mathrm{~A}$ título de exemplo, e como resultados dos estudos REA, evidencia-se o composto 56 (Figura 7C), o qual possui uma cadeia alquinila na posição C8 do núcleo da purina.

Dos vários estudos efetuados nesta área, os quais incidiram na introdução de modificações estruturais em $N^{6}$ e C2, concluiu-se que a substituição na posição $N^{6}$ é determinante no controlo da eficácia, revertendo a atividade agonista de alguns derivados da adenosina. . $2,27^{2}$

A influência da conformação do anel de ribose na afinidade e ativação dos RA $\mathrm{A}_{3}$ foi também explorada tendo-se efetuado, por exemplo, a síntese de análogos do IB-MECA com restrição de rotação conformacional do anel do açúcar (composto 57, Figura 7C) ${ }^{64}$ Posteriormente identificaram-se derivados $4^{\prime}$-tioadenosina como novos scaffolds para o desenho de antagonistas RA $\mathrm{A}_{3}{ }^{65}$ Interessante ainda realçar neste contexto, os estudos em que os agonistas Cl-IB-MECA e o seu análogo 4’-tio foram convertidos em antagonistas pela introdução de um segundo grupo $N$-metila na posição $5^{\prime}$-uronamida (compostos 58 e 59, Figura 7C). A remoção completa do substituinte em 4' levou ainda à identificação de uma nova série de potentes e seletivos antagonistas RA $\mathrm{A}_{3}$ (composto 60, Figura 7C). Melman et al. ${ }^{66}$ propuseram ainda uma nova família de antagonistas nos quais ocorre a remoção completa da função $N$ metilcarboxamida (composto 61, Figura 7C). Os estudos efetuados nesta área ainda englobaram a substituição da ribose por anéis não heterocíclicos e a avaliação das preferências estereoquímicas da interação ligante-receptor. De salientar que os enantiómeros do tipo L apresentaram ausência de afinidade para todos os tipos de receptores.

\section{Moduladores alostéricos}

No sentido de aumentar a afinidade e eficácia dos agonistas ou dos antagonistas foi também efetuado o desenvolvimento de moduladores alostéricos positivos (PAMs, - positive allosteric modulators) para o RA A $3 .{ }^{67}$ Embora o número de compostos desenvolvidos seja ainda reduzido salientam-se os resultados obtidos pela equipa de Jacobson e colaboradores ${ }^{68,69}$ e pela de Heitman et al. ${ }^{70}$ os quais propuseram novos scaffolds para a obtenção de PAMs. 


\section{CONCLUSÕES}

A resposta limitada dos tumores malignos à quimioterapia convencional levou ao desenvolvimento de novas estratégias farmacológicas baseadas no conhecimento de novos alvos terapêuticos os quais se encontram envolvidos na motilidade de células cancerígenas, invasão e formação de metástases.

$\mathrm{O}$ conhecimento adquirido até à data em relação aos receptores da adenosina, nomeadamente em relação à biologia molecular do $\mathrm{RA} \mathrm{A}_{3}$, forneceu uma base sólida que levou à proposta deste receptor como um novo alvo terapêutico para o câncer, possibilitando o desenho racional, e ao desenvolvimento de ligantes potentes e seletivos para o RA $\mathrm{A}_{3}$. É importante salientar que, como ainda não existem dados cristalográficos do RA $\mathrm{A}_{3}$, o avanço do conhecimento das suas funções biológicas e bioquímicas foi efetuado a partir da informação adquirida com os ligantes sintéticos. Na verdade, o desenvolvimento de novos agonistas e/ou antagonistas e/ou moduladores alostéricos RA $A_{3}$ tem tido um crescimento exponencial, sendo uma área de crescente interesse na Química Medicinal. O fluxo constante das novas informações obtidas poderá conduzir, por um lado, a um melhor conhecimento do receptor e, por outro, ao desenvolvimento de candidatos para aplicação em terapia. Deve-se salientar que embora tenha havido uma ativa investigação ainda não se obteve o candidato ideal, embora alguns compostos estejam em estudos de fase clínica (e.g. IB-MECA e Cl-IB-MECA).

O desenvolvimento paralelo das metodologias de modelagem molecular do $\mathrm{RA} \mathrm{A}_{3}{ }^{71,72}$ e de técnicas de $\mathrm{REAQ}^{73-76}$ a que atualmente se assiste abre portas para uma melhor interpretação dos dados de REA e uma otimização mais eficiente dos compostos líderes. Acredita-se também que o desenvolvimento de biased agonistas e a aplicação dos conceitos e técnicas de nanotecnologia possam levar a um novo impulso nesta área de pesquisa. A recente descoberta de dendrímeros que ativam simultaneamente dois receptores GPCR (receptores A3 e o receptor purínico- P2Y14) é uma validação deste novo desafio. ${ }^{77-79}$

\section{AGRADECIMENTOS}

À Fundação para a Ciência e Tecnologia (Portugal) pelo apoio financeiro relativo ao projeto PTDC/QUI/70359/2006 e à bolsa de doutoramento de A. Gaspar (FCT SFRH/BD/43531/2008).

\section{REFERÊNCIAS}

1. Fredholm, B. B.; Cell. Death. Differ. 2007, 14, 1315.

2. Fredholm, B. B.; Exp. Cell Res. 2010, 316, 1284.

3. Jacobson, K. A. Em Adenosine Receptors in Health and Disease; Wilson, C. N.; Mustafa, S. J., eds.; Springer:Verlag: Heidelberg, 2009, vol. 193.

4. Fredholm, B. B.; Jacobson, K. A.; Heterocycles 2009, 79, 73.

5. Moro, S.; Gao, Z. G.; Jacobson, K. A.; Spalluto, G.; Med. Res. Rev. 2006, 26, 131.

6. Catarzi, D.; Colotta, V.; Varano, F.; Calabri, F. R.; Lenzi, O.; Filacchioni, G.; Trincavelli, L.; Martini, C.; Tralli, A.; Montopoli, C.; Moro, S.; Bioorg. Med. Chem. 2005, 13, 705.

7. Silva, B. V.; Horta, B. A. C.; Alencastro, R. B.; Pinto, A. C.; Quim. Nova 2009, 32, 453 .

8. Fishman, P.; Bar-Yehuda, S.; Varani, K.; Gessi, S.; Merighi, S.; Borea, P. A. Em A3 adenosine receptors- from Cell Biology to Pharmacology and Therapeutics; Borea, P. A., ed.; $1^{\text {st }}$ ed.; Springer: Dordrecht/Heidelberg/ London/New York, 2010, cap 16.

9. Almeida, V. L.; Leitão A.; Luisa Reina, C. B.; Montanari, C. A.; Donnici, C. L.; Quim. Nova 2005, 28, 118.
10. Baraldi, P. G.; Cacciari, B.; Romagnoli, R.; Merighi, S.; Varani, K.; Borea, P. A.; Spalluto, G.; Med. Res. Rev. 2000, 20, 103.

11. Diniz, C.; Borges, F.; Santana, L.; Uriarte, E.; Oliveira, J. M. A.; Gonçalves, J.; Fresco, P.; Curr. Pharm. Des. 2008, 14, 1698.

12. Merighi, S.; Mirandola, P.; Varani, K.; Gessi, S.; Leung, E.; Baraldi, P. G.; Tabrizi, M. A.; Borea, P. A.; Pharmacol. Ther. 2003, 100, 31.

13. Fishman, P.; Jacobson, K. A.; Ochaion, A.; Cohen, S.; Bar-Yehuda, S.; Immunol. Endocr. Metab. Agents Med. Chem. 2007, 7, 298.

14. Gessi, S.; Merighi, S.; Varani, K.; Leung, E.; Mac Lennan, S.; Borea, P. A.; Pharmacol. Ther. 2008, 117, 123.

15. Kim, S. J.; Min, H. Y.; Chung, H. J.; Park, E. J.; Hong, J. Y.; Kang, Y. J.; Shin, D. H.; Jeong, L. S.; Lee, S. K.; Cancer Lett. 2008, 264, 309.

16. Bertout, J. A.; Patel, S. A.; Simon, M. C.; Nat. Rev. Cancer 2008, 8, 967.

17. Blay, J.; White, T. D.; Hoskin, D. W.; Cancer Res. 1997, 57, 2602.

18. Feoktistov, I.; Ryzhov, S.; Goldstein, A. E.; Biaggioni, I.; Circ. Res. 2003, $92,485$.

19. Merighi, S.; Benini, A.; Mirandola, P.; Gessi, S.; Varani, K.; Leung, E.; MacLennan, S.; Baraldi, P. G.; Borea, P. A.; Neoplasia 2005, 7, 894.

20. Merighi, S.; Benini, A.; Mirandola, P.; Gessi, S.; Varani, K.; Simioni, C.; Leung, E.; Maclennan, S.; Baraldi, P. G.; Borea, P. A.; Mol. Pharmacol. 2007, 72, 395 .

21. Madi, L.; Bar-Yehuda, S.; Barer, F.; Ardon, E.; Ochaion, A.; Fishman, P.; J. Biol. Chem. 2003, 278, 42121.

22. Baraldi, P. G.; Romagnoli, R.; Saponaro, G.; Baraldi, S.; Tabrizi, M. A. D. P. Em ref. 8, cap. 7.

23. Tchilibon, S.; Kim, S. K.; Gao, Z. G.; Harris, B. A.; Blaustein, J. B.; Gross, A. S.; Duong, H. T.; Melman, N.; Jacobson, K. A.; Bioorg. Med. Chem. 2004, 12, 2021.

24. Jacobson, K. A.; Gao, Z. G.; Tosh, D. K.; Sanjayan, G. J.; Castro, S. Em ref. 8, cap. 6 .

25. Joshi, B. V.; Jacobson, K. A.; Curr. Top. Med Chem. 2005, 5, 1275.

26. Gao, Z. G.; Blaustein, J. B.; Gross, A. S.; Melman, N.; Jacobson, K. A.; Biochem. Pharmacol. 2003, 65, 1675.

27. Baraldi, P. G.; Cacciari, B.; De Las Infantas, M. J. P.; Romagnoli, R.; Spalluto, G.; Volpini, R.; Costanzi, S.; Vittori, S.; Cristalli, G.; Melman, N.; Park, K. S.; Ji, X. D.; Jacobson, K. A.; J. Med. Chem. 1998, 41, 3174.

28. Gao, Z. G.; Mamedova, L. K.; Chen, P.; Jacobson, K. A.; Biochem. Pharmacol. 2004, 68, 1985.

29. Elzein, E.; Palle, V.; Wu, Y.; Maa, T.; Zeng, D.; Zablocki, J.; J. Med. Chem. 2004, 47, 4766.

30. Cosyn, L.; Palaniappan, K. K.; Kim, S. K.; Duong, H. T.; Gao, Z. G.; Jacobson, K. A.; van Calenbergh, S.; J. Med. Chem. 2006, 49, 7373.

31. Ohno, M.; Gao, Z. G.; van Rompaey, P.; Tchilibon, S.; Kim, S. K.; Harris, B. A.; Gross, A. S.; Duong, H. T.; van Calenbergh, S.; Jacobson, K. A.; Bioorg Med.Chem. 2004, 12, 2995.

32. DeNinno, M. P.; Masamune, H.; Chenard, L. K.; DiRico, K. J.; Eller, C.; Etienne, J. B.; Tickner, J. E.; Kennedy, S. P.; Knight, D. R.; Kong, J.; Oleynek, J. J.; Tracey, W. R.; Hill, R. J.; Bioorg. Med. Chem. Lett. 2006, 16, 2525.

33. DeNinno, M. P.; Masamune, H.; Chenard, L. K.; DiRico, K. J.; Eller, C.; Etienne, J. B.; Tickner, J. E.; Kennedy, S. P.; Knight, D. R.; Kong, J.; Oleynek, J. J.; Tracey, W. R.; Hill, R. J.; J. Med. Chem. 2003, $46,353$.

34. Kim, S. K.; Gao, Z. G.; Jeong, L. S.; Jacobson, K. A.; J. Mol. Graphics Modell. 2006, 25, 562.

35. Jeong, L. S.; Jin, D. Z.; Kim, H. O.; Shin, D. H.; Moon, H. R.; Gunaga, P.; Chun, M. W.; Kim, Y.-C.; Melman, N.; Gao, Z.-G.; Jacobson, K. A.; J. Med. Chem. 2003, 46, 3775.

36. Beukers, M. W.; Chang, L. C. W.; von Frijtag, D. K. J. K.; MulderKrieger, T.; Spanjersberg, R. F.; Brussee, J.; Ijzerman, A. P.; J. Med. Chem. 2004, 47, 3707.

37. Gao, Z. G.; Jacobson, K. A.; Pharmacol. Res. 2008, 57, 303. 
38. Baraldi, P. G.; Tabrizi, M. A.; Preti, D.; Bovero, A.; Fruttarolo, F.; Romagnoli, R.; Zaid, N. A.; Moorman, A. R.; Varani, K.; Borea, P. A.; J. Med. Chem. 2005, 48, 5001.

39. Jacobson, K. A.; Ji, X. D.; Li, A. H.; Melman, N.; Siddiqui, M. A.; Shin, K. J.; Marquez, V. E.; Ravi, R. G.; J. Med. Chem. 2000, 43, 2196.

40. Karton, Y.; Jiang, J.-1.; Ji, X-D.; Melman, N.; Olah, M. E.; Stiles, G. L.; Jacobson, K. A.; J. Med. Chem. 1996, 39, 2293.

41. Linden, J.; Trends Pharmacol. Sci. 1994, 15, 298.

42. Ji, X-D.; von Lubitz, D.; Olah, M. E.; Stiles, G. L.; Jacobson, K. A.; Drug Dev. Res. 1994, 33, 51.

43. Ji, X-D.; Melman, N.; Jacobson, K. A.; J. Med. Chem. 1996, 39, 781.

44. Ismail, N. A.; Shaheen, A. A.; El-Sawalhi, M. M.; Megahed, Y. M.; Arzneimittel-Forschung/Drug Research 1995, 45, 865.

45. Jiang, J-L.; van Rhee, A. M.; Chang, L.; Patchornik, A.; Ji, X-D.; Evans, P.; Melman, N.; Jacobson, K. A.; J. Med. Chem. 1997, 40, 2596.

46. Moro, S.; Li, A. H.; Jacobson, K. A.; J. Chem. Inf. Comput. Sci. 1998, $38,1239$.

47. Li, A-H.; Moro, S.; Melman, N.; Ji, X-D.; Jacobson, K. A.; J. Med. Chem. 1998, 41, 3186.

48. Kim, Y-C.; de Zwart, M.; Chang, L.; Moro, S.; von Frijtag, D. K. J. K.; Melman, N.; Ijzerman, A. P.; Jacobson, K. A.; J. Med. Chem. 1998, 41, 2835 .

49. Okamura, T.; Kurogi, Y.; Hashimoto, K.; Sato, S.; Nishikawa, H.; Kiryu, K.; Nagao, Y.; Bioorg. Med. Chem. Lett. 2004, 14, 3775.

50. van Muijlwijk-Koezen, J. E.; Timmerman, H.; Link, R.; van der Goot, H.; Ijzerman, A. P.; J. Med. Chem. 1998, 41, 3987.

51. van Muijlwijk-Koezen, J. E.; Timmerman, H.; Link, R.; van der Goot, H.; Uzerman, A. P.; J. Med. Chem. 1998, 41, 3994.

52. van Muijlwijk-Koezen, J. E.; Timmerman, H.; van Der Goot, H.; Menge, W. M. P. B.; von Drabbe, K. J. F.; De Groote, M.; Ijzerman, A. P.; J. Med. Chem. 2000, 43, 2227.

53. Colotta, V.; Catarzi, D.; Varano, F.; Cecchi, L.; Filacchioni, G.; Martini, C.; Trincavelli, L.; Lucacchini, A.; J. Med. Chem. 2000, 43, 3118.

54. Colotta, V.; Catarzi, D.; Varano, F.; Capelli, F.; Lenzi, O.; Filacchioni, G.; Martini, C.; Trincavelli, L.; Ciampi, O.; Pugliese, A. M.; Pedata, F.; Schiesaro, A.; Morizzo, E.; Moro, S.; J. Med. Chem. 2007, 50, 4061.

55. Colotta, V.; Catarzi, D.; Varano, F.; Lenzi, O.; Filacchioni, G.; Martini, C.; Trincavelli, L.; Ciampi, O.; Traini, C.; Pugliese, A. M.; Pedata, F.; Morizzo, E.; Moro, S.; Bioorg. Med. Chem. 2008, 16, 6086.

56. Varani, K.; Merighi, S.; Gessi, S.; Klotz, K. N.; Leung, E.; Baraldi, P. G.; Cacciari, B.; Romagnoli, R.; Spalluto, G.; Borea, P. A.; Mol. Pharmacol. 2000, 57, 968

57. Lenzi, O.; Colotta, V.; Catarzi, D.; Varano, F.; Poli, D.; Filacchioni, G.; Varani, K.; Vincenzi, F.; Borea, P. A.; Paoletta, S.; Morizzo, E.; Moro, S.; J. Med. Chem. 2009, 52, 7640.
58. Biagi, G.; Bianucci, A. M.; Coi, A.; Costa, B.; Fabbrini, L.; Giorgi, I.; Livi, O.; Micco, I.; Pacchini, F.; Santini, E.; Leonardi, M.; Nofal, F. A.; Salerni, O. L.; Scartoni, V.; Bioorg. Med. Chem. 2005, 13, 4679.

59. Okamura, T.; Kurogi, Y.; Nishikawa, H.; Hashimoto, K.; Fujiwara, H.; Nagao, Y.; J. Med. Chem. 2002, 45, 3703.

60. Priego, E. M.; Pérez-Pérez, M. J.; von Frijtag, D. K. J. K.; De Vries, H.; Ijzerman, A. P.; Camarasa, M. J.; Martín-Santamaría, S.; ChemMedChem. 2008, 3, 111.

61. Baraldi, P. G.; Tabrizi, M. A.; Gessi, S.; Borea, P. A.; Chem. Rev. 2008 , 108, 238.

62. Müller, C. E.; Thorand, M.; Qurishi, R.; Diekmann, M.; Jacobson, K. A.; Padgett, W. L.; Daly, J. W.; J. Med. Chem. 2002, 45, 3440.

63. Volpini, R.; Costanzi, S.; Lambertucci, C.; Vittori, S.; Klotz, K. N.; Lorenzen, A.; Cristalli, G.; Bioorg. Med. Chem. Lett. 2001, 11, 1931.

64. Ravn, J.; Qvortrup, K.; Rosenbohm, C.; Koch, T.; Bioorg. Med. Chem. 2007, 15,5440 .

65. Jeong, L. S.; Choe, S. A.; Gunaga, P.; Kim, H. O.; Lee, H. W.; Lee, S. K.; Tosh, D. K.; Patel, A.; Palaniappan, K. K.; Gao, Z-G.; Jacobson, K. A.; Moon, H. R.; J. Med. Chem. 2007, 50, 3159.

66. Melman, A.; Gao, Z-G.; Kumar, D.; Wan, T. C.; Gizewski, E.; Auchampach, J. A.; Jacobson, K. A.; Bioorg. Med. Chem. Lett. 2008, 18, 2813.

67. Gao, Z-G.; van Muijlwijk-Koezen, J. E.; Chen, A.; Müller, C. E.; Ijzerman, A. P.; Jacobson, K. A.; Mol. Pharmacol. 2001, 60, 1057.

68. Gao, Z-G.; Kim, S. G.; Soltysiak, K. A.; Melman, N.; Ijzerman, A. P.; Jacobson, K. A.; Mol. Pharmacol.2002, 62, 81.

69. Kim, Y.; Castro, S.; Gao, Z-G.; Ijzerman, A. P.; Jacobson, K. A.; J. Med. Chem. 2009, 52, 2098.

70. Heitman, L. H.; Göblyös, A.; Zweemer, A. M.; Bakker, R.; MulderKrieger, T.; van Veldhoven, J. P. D.; De Vries, H.; Brussee, J.; Ijzerman, A. P.; J. Med. Chem. 2009, 52, 926.

71. Moro, S.; Curr. Pharm. Des. 2009, 15, 3992

72. Morizzo, E.; Federico, S.; Spalluto, G.; Moro, S.; Curr. Pharm. Des. 2009, 15, 4069 .

73. González, M. P.; Terán, C.; Teijeira, M.; Med. Res. Rev. 2008, $28,329$.

74. Tintori, C.; Manetti, F.; Botta, F.; Curr. Top. Med. Chem. 2010, 10, 1019.

75. Sharma, S.; Sharma, B. K.; Sharma, S. K.; Singh, P.; Prabhakar, Y. S.; Eur. J. Med. Chem. 2009, 44, 1377.

76. Cruz-Monteagudo, M.; Cordeiro, M. N. D. S.; Teijeira, M.; González, M. P.; Borges, F.; Chem. Biol. Drug Des. 2010, 75, 607.

77. Klutz, A. M.; Gao, Z-G.; Lloyd, J.; Shainberg, A.; Jacobson, K. A.; J. Nanobiotechnology 2008, 6, 12.

78. Kim, Y.; Hechler, B.; Gao, Z-G.; Gachet, C.; Jacobson, K. A.; Bioconjug. Chem. 2009, 20, 1888.

79. Tosh, D. K.; Yoo, L. S.; Chinn, M.; Hong, K.; Kilbey Ii, S. M.; Barrett, M. O.; Fricks, I. P.; Harden, T. K.; Gao, Z-G.; Jacobson, K. A.; Bioconjug. Chem. 2010, 21, 372. 